\title{
Body Stalk Syndrome: Case Follow Up and Literature Review
}

\author{
Joaquín Bustillos*, Cinthia Cruz, Tatiana Quijano, Pablo Parra, Eugenio Calderón, \\ Verónica Saborío, Jorge Mora
}

Faculty of Medicine, University of Costa Rica, San José, Costa Rica

\section{Email address:}

joaquin.bustillos@gmail.com (J. Bustillos), cinthiacruz@gmail.com (C. Cruz), tatianaquijanomd@gmail.com (T. Quijano), drpabloparra@gmail.com (P.Parra),drrock.eugenio@gmail.com (E. Calderón), sabolopez@yahoo.com (V.Saborío),

joramoras@gmail.com (J. Mora)

${ }^{*}$ Corresponding author

\section{To cite this article:}

Joaquín Bustillos, Cinthia Cruz, Tatiana Quijano, Pablo Parra, Eugenio Calderón, Verónica Saborío, Jorge Mora. Body Stalk Syndrome: Case Follow Up and Literature Review. Journal of Gynecology and Obstetrics. Vol. 6, No. 1, 2018, pp. 11-14. doi: 10.11648/j.jgo.20180601.13

Received: February 1, 2018; Accepted: February 16, 2018; Published: March 15, 2018

\begin{abstract}
A case of body stalk anomaly which was diagnosed at 17 weeks of gestation is presented on a second trimester sonography after an abnormal first trimester scan and second opinion review. The fetus displayed multiple anomalies characteristic of body stalk syndrome including abdominal wall defect (omphalocele), kyphoscoliosis, fetal dismorphology and a two vesseled umbilical cord. Body stalk anomaly is a rare congenital anomaly with a series of similar clinical manifestations and poor prognosis.
\end{abstract}

Keywords: Body Stalk, Body Stalk Syndrome, Body Stalk Anomaly, Abdominal Wall Defect, Multiple Anomalies

\section{Background}

The presence of body wall defects with thoracic and abdominal organs evisceration associated to other congenital anomalies with or without extremities alterations, are denominated as "complex body wall defects". [1] [2] There are plenty differences, but three morphological entities have been established, more or less, well defined: body stalk anomaly, limb body wall/body wall complex and amniotic band sequence with body wall envolvement, all with uniformly unfavorable prognosis. [1] [2] [3] [4]

Body stalk anomalies refer to a group of lethal malformations in which abdominal wall defects are so significant. The abdominal, and often thoracic, organs lie outside the body cavity and within a membrane composed of amnion and peritoneum. [4] This sac is most often directly attached to the placenta. [2] The main features of this abnormality are large complex cranial defects (eg, encephalocele), facial clefts, body wall defects of the thorax and/or abdominal wall, and the umbilical cord may be totally absent or extremely shortened. [4]

\section{Objective}

The main objective of this work is to review a lethal fetal anomaly not so uncommon in clinical practice and to expose the prenatal approach in the case in which pregnancy is continued.

\section{Method}

A 19-year-old primigravid woman with uncertain menstrual dates was referred for an ultrasound scan and higher risk pregnancy control for being a teenager from a risky population. She was not using contraception and her cycles were irregular. As relevant medical history she had been treated for anal condiloma and was an active smoker until 8 weeks pregnant. She has cocaine and marihuana frequent consumption story.

Transabdominal ultrasound was completed, and showed omphalocele, kyphoscoliosis and a shortened and rudimentary umbilical cord, the measurements were consistent with a gestational age of 17 weeks and 1 day. The amniotic membrane was not assessable. 
The patient was counseled that this is a lethal condition for the fetus and the prognosis was poor, and because of the legislation in Costa Rica there are no medical termination options.

\section{Results}

A pregnancy clinical surveillance with suspicion of fetal malformation was undertake as follows:

At 19 weeks of gestation, genetic amniocentesis was performed with no complications. At 20 weeks, ultrasound findings are confirmed showing the content of abdominal wall defect (liver, small bowel and bladder). Kyphoscoliosis was severe and the short cord had only two vessels instead of three Figure 1.

At week 26, the abdominal defect became larger and its content became in intimate touch with the placenta Figure 2.

At week 34, the defect became $65 \mathrm{~mm}$ long, and contained liver, stomach, left kidney and small bowel, and impressed to be attached to the placenta Figure 3.

The fetus was born at 35 weeks and died 5 hours after birth, and pathological findings confirmed body stalk anomaly, describing also interauricular communication, lung hypoplasia, absence of ductus arteriosus and intraperitoneal organ adhesion to placenta. The amniotic membrane was continuous with the skin of the body wall defect Figure 4.

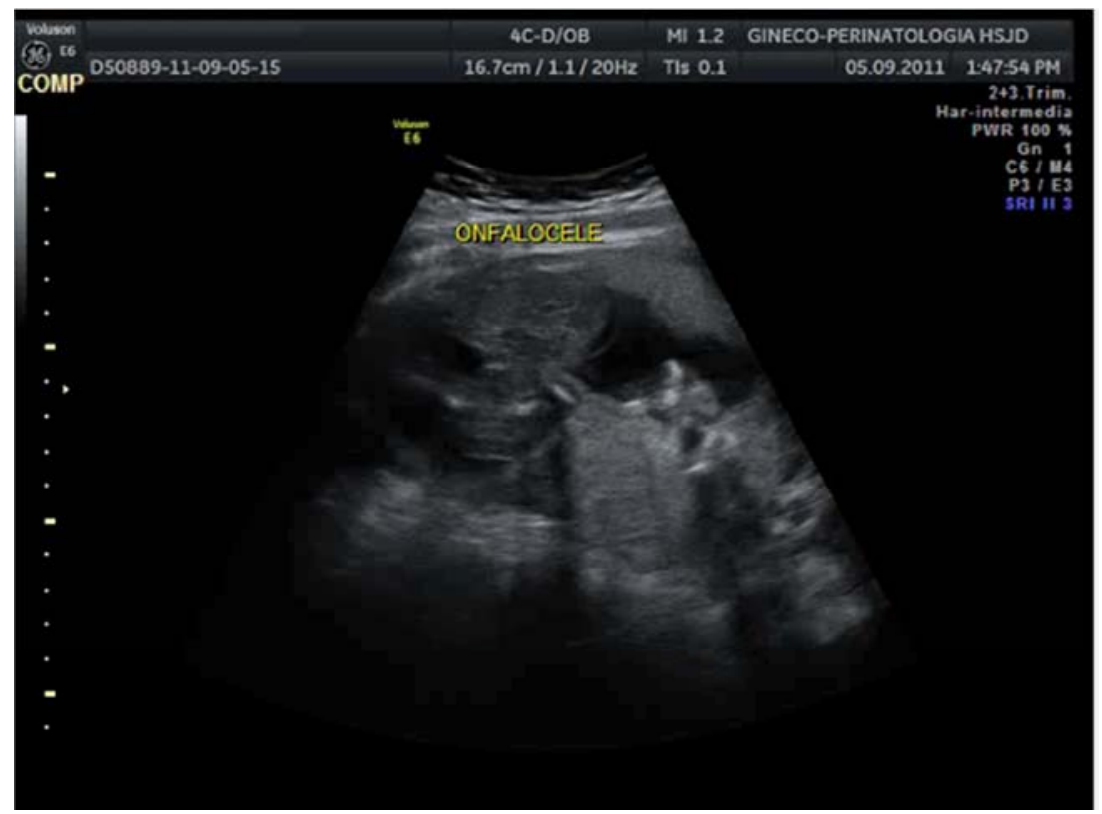

Figure 1. At 19 weeks of gestation, genetic amniocentesis was performed with no complications. At 20 weeks, ultrasound findings are confirmed showing the content of abdominal wall defect (liver, small bowel and bladder). Kyphoscoliosis was severe and the short cord had only two vessels instead of three.

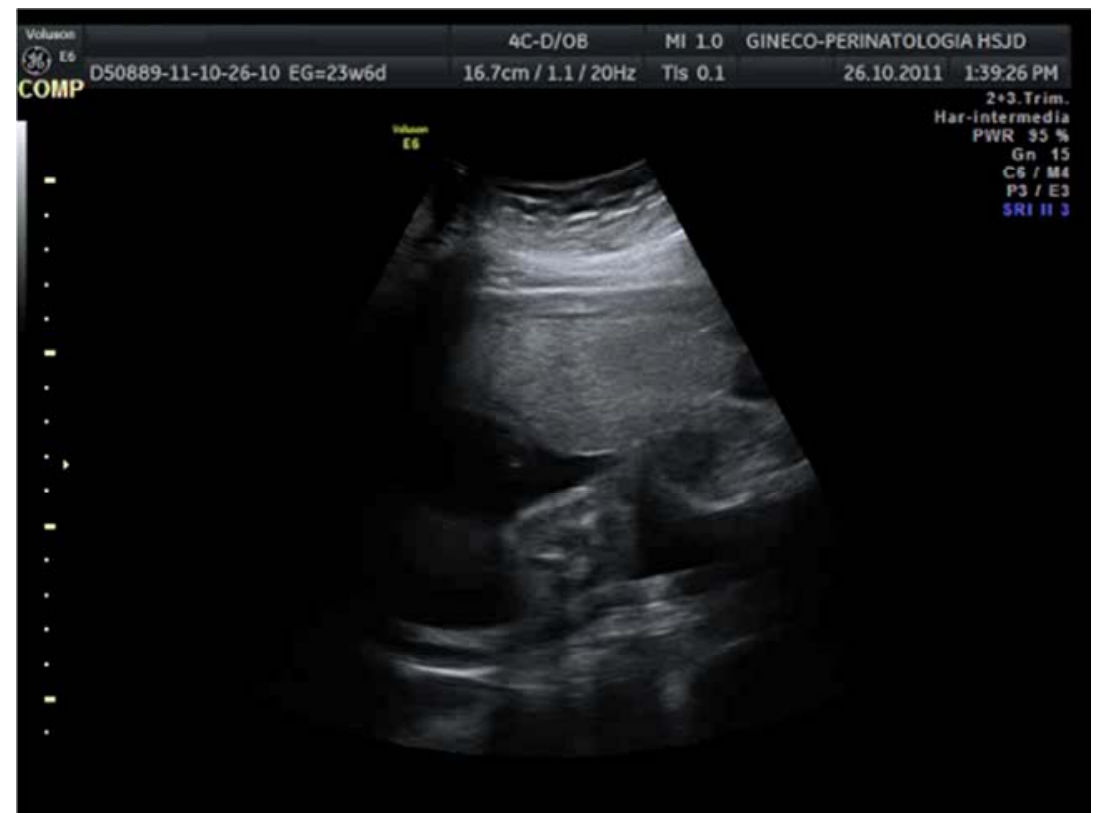

Figure 2. Week 26. The abdominal defect became larger and its content became in intimate touch with the placenta. 


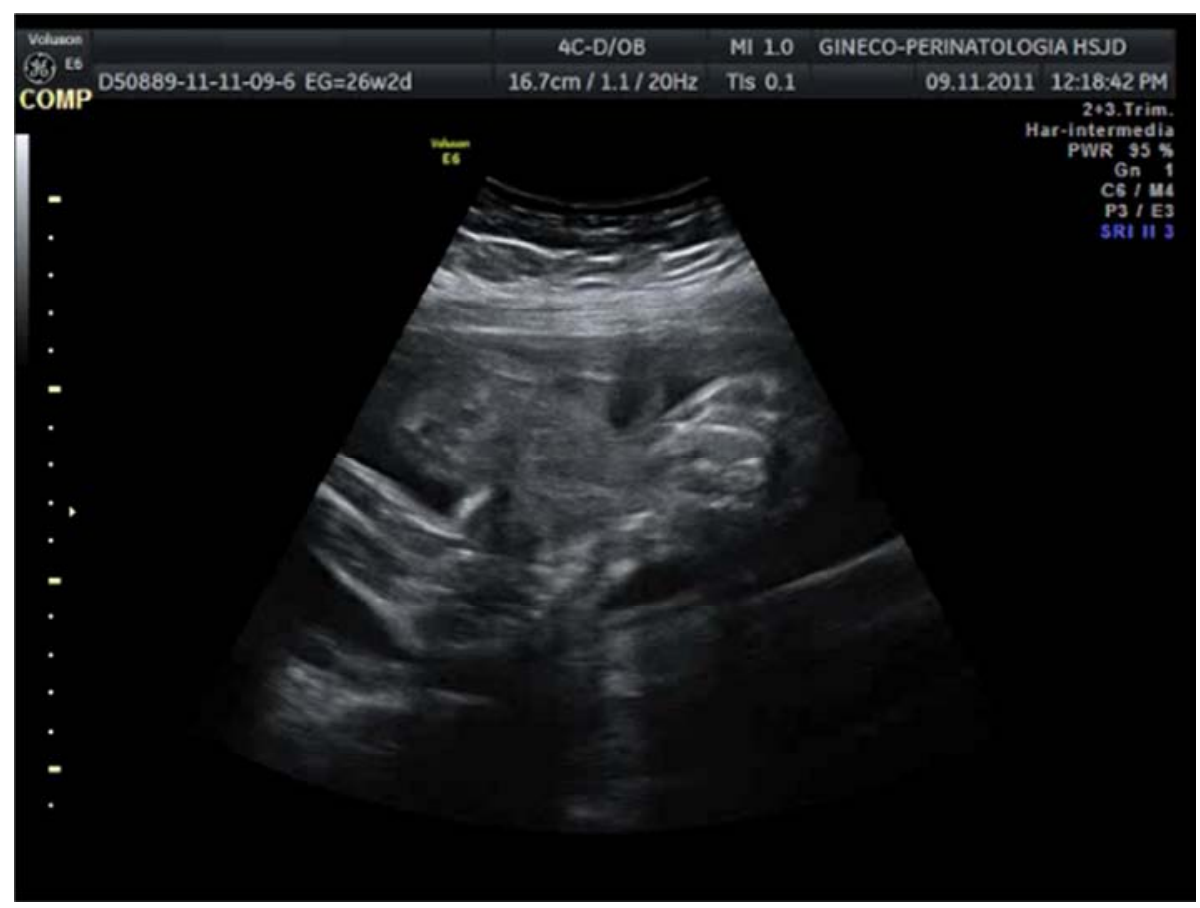

Figure 3. Week 34. The defect became $65 \mathrm{~mm}$ long, and contained liver, stomach, left kidney and small bowel, and impressed to be attached to the placenta.

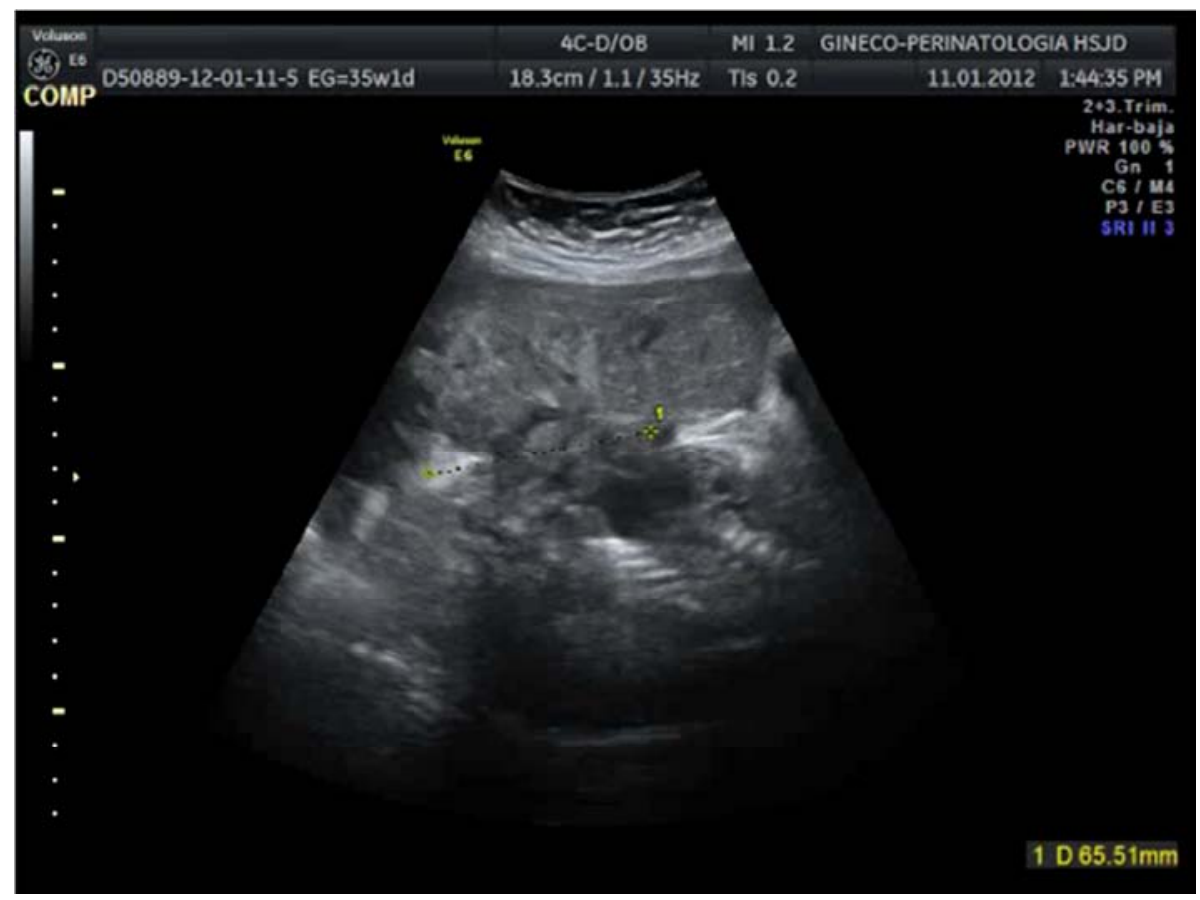

Figure 4. The fetus was born at 35 weeks and died 5 hours after birth, and pathological findings confirmed body stalk anomaly, describing also interauricular communication, lung hypoplasia, absence of ductus arteriosus and intraperitoneal organ adhesion to placenta. The amniotic membrane was continuous with the skin of the body wall defect.

\section{Discussion}

Body stalk anomaly, includes all disorders in which exists absence or shortening of umbilical cord, or in which there is continuity between the abdominal wall and the placenta. [4] [5]

The incidence of body stalk anomaly/limb body wall complex varies with literature, being no more frequent than
$1 / 100.000$ live births; recent publications show that most cases are sporadic, $50 \%$ cases are associated with maternal smoking, 50\% cases associated with maternal alcohol use and $40 \%$ had prior infant with congenital anomaly. [5] [6] [7]

Embryologically, body stalk/limb-body wall complex disorders occur from failure of fusion of all 4 embryonic disc folds during the 6th postmenstrual week. [8] [9] Normally, after the embryo folds, the intra-embryonic coelom (future peritoneal cavity) is separated from the extra-embryonic 
coelom, and the umbilical cord subsequently forms. If this folding does not occur, then the extra-embryonic cavity is not obliterated and the body stalk is missing. [8] [9]

Herniation of abdominal contents into the amnioperitoneal sac occurs owing to lack of lateral folding. Additionally, abnormal caudal folding results in the malformations noted with cloacal exstrophy. [10] Severe scoliosis develops as a consequence of the irregular attachment of the fetus to the placenta. [1]

This syndrome is often detected by prenatal ultrasound in the second trimester. [7] A combination of scoliosis and omphalocele should suggest this diagnosis, which has been made as early as the 9 th postmenstrual week. [1]

Criteria for first trimester ultrasound diagnosis include demonstration of the internal viscera in the extra-embryonic coelom and a short, 2-vessel umbilical cord. [6]

Differential diagnosis includes amniotic band syndrome. [4] Associated abnormalities include craniofacial abnormalities (encephalocele, holocranium), midfacial clefts, increased nuchal translucency, limb defects, and significant skeletal abnormalities. [2] This abnormality is always lethal.

There are several theories that pretend to explain the development of the body stalk one refers to the premature rupture of the amnios, with partial embryonic pole output to the extraembryonic coelom. [11] [12] [13] Against this theory, there have been body stalk anomaly diagnoses using ultrasound that showed intact amniotic membrane at ages as early as 10 weeks. [12]

Another theory suggests that there is an specific defect during plication of the trilaminar embryo, but without knowing the cause completely. [14] In Van Allen et al series of 25 cases, the amniotic membrane was continuous with the skin of the body wall defect in $85 \%$, which is consistent with the theory of developmental anomaly. [15]

The majority of the cases have shown an increased nuchal translucency, therefore and as one of the major congenital chromosomopathies marker, it is always recommended to do it between 11-13.6 weeks. [8]

If there is olygoamnios associated, renal malformations should be discarded. [4] There are no chromosomal abnormalities associated to this defect. [9]

There is no intrauterus procedure known to treat the fetus. The prognosis is lethal so the regular viability control must be strict. [4]

\section{Conclusion}

In conclusion the present case illustrates the fact that an early defect of embryo folding would compromise the development of the body stalk, and it represents just an smaller branch of a wide variety of midline body wall defects that morphologically, depend on the phase of development that they affect, in this specific case, meeting all criteria of body stalk anomaly, as explained earlier.

\section{References}

[1] Paul C, Zosmer N, Jurkovic D and et all. A case of body stalk anomaly at 10 weeks of gestation. Ultrasound Obstet Gynecol 2001; 17: 157- 159 .

[2] Fountaine E, Knight K. Ultrasound for Abdominal Wall Defects. Ultrasound Clin 2013; 8; 55-67.

[3] Adonakis G, Spinos N, Tourikis J, et all. A case of body stalk anomaly at 12 weeks of gestation. Clin Esp Obstet Gynecol. 2008; 35 (3): 218-20.

[4] Smerck JM, Germer U, Krokowski M, et al. Prenatal ultrasound diagnosis and management of body stalk anomaly: analysis of nine singleton and two multiple pregnancies. Ultrasound Obstet Gynecol 2003; 21 (4); 322-8.

[5] Djakovic A, Blissing S, Volker Hu, et all. Body Stalk anomaly: a case report on a rare congenital defect. Zentraibi Gynakol. 2006; 128 (6); 369-71.

[6] Ginsberg NE, Cadkin A, Strom C. Prenatal diagnosis of body stalk anomaly in the first trimester of pregnancy. Ultrasound Obstet Gynecol. 1997; 10 (6); 419-21.

[7] Daskalakis G, Pilalis A, Papadopodulos D, et all. Body Stalk anomaly diagnosed in the 2nd trimester. Fetal Diagn Ther. 2003; 18 (5) 342-4.

[8] Gratacos E, Gomez R, Nicoilades K, et all. Medicina Fetal 1 edición. España Editorial Medica Panamericana 2009; 415418.

[9] Smith, Jones. Patrones reconocibles de malformaciones humanas 6 edición. España. Elsevier 2007; 368-370.

[10] Quijano F, Rey M, Echeverry M, et all. Body Stalk anomaly in a 9 week pregnancy. Case reports in Obstetrics and Gynecology 2014; 357285.

[11] Murphy A, Platt L. First- trimester diagnosis of body stalk anomaly using 2 and 3 dimensional sonography. J Ultrasound Med. 2011; 30 (12); 1739-43.

[12] Daskalakis G, Sebire NJ, Jurkovic D, et all. Body Stalk anomaly at 10-14 weeks of gestation. Ultrasound Obstet Gynecol 1997; 10 (6); 416-8.

[13] Martinez J, Fortuny A, Comas C, et all. Body stalk anomaly associated with maternal cocaine abuse. Prenat Diagn 1994; $14 ; 669-672$.

[14] Van Allen M, Curry C, Gallagher L. Limb- body wall complex: pathogenesis. Am J Med Genet 1987; 28; 529-48.

[15] Van Allen M, Curry C, Walden C, et all. Limb-body wall complex: limb and spine defects. Am J Med Genet 1987; 28; 549-65. 